\title{
Comparison and ranking of Swiss railway incident data from 2000-2009
}

\author{
G. Buxhoeveden ${ }^{1}$, E. Schnieder ${ }^{1}$, R. Slovak ${ }^{2}$ \& H. Meuli ${ }^{2}$ \\ ${ }^{1}$ Institute for Traffic Safety and Automation Engineering, \\ Braunschweig, Germany \\ ${ }^{2}$ Federal Office of Transport, Bern, Switzerland
}

\begin{abstract}
Supervision of the safety performance in public transport is one of the main tasks of the Federal Office of Transport (FOT) in Switzerland. Recently a three level system of safety indicators has been defined to cover all means of Swiss public transport. The safety indicators are fed by the FOT incident database since the year 2000 and it is covering all transport companies having a license to operate in Switzerland. In cooperation with the Institute for Traffic Safety and Automation Engineering (iVA) at Technical University Braunschweig, Germany, FOT is developing a suitable methodology for the definition and evaluation of the safety targets in Swiss public transport. The methodology is applied for evaluation of safety indicators on a country level and for single transport companies, taking into account the statistical significance of the rare events incident data, which very often cannot be interpreted by conventional methods of data analyses based on simple averaging.
\end{abstract}

Keywords: statistical analysis, safety, risk, scale, ranking, railway, public transport, Switzerland.

\section{System of safety indicators, motivation and overview}

Long term railway accident analyses on an aggregated level are being carried out on a regular basis $[1,2]$. Due to lack of in-depth data, incidents are usually not categorised. With railway incident data from Switzerland a categorisation of data was possible and is described in this paper. According to the Safety Concept of the Federal Office of Transport [3] the safety in the Swiss public transport must be kept on the present level, despite the rise of transportation volume. For this 


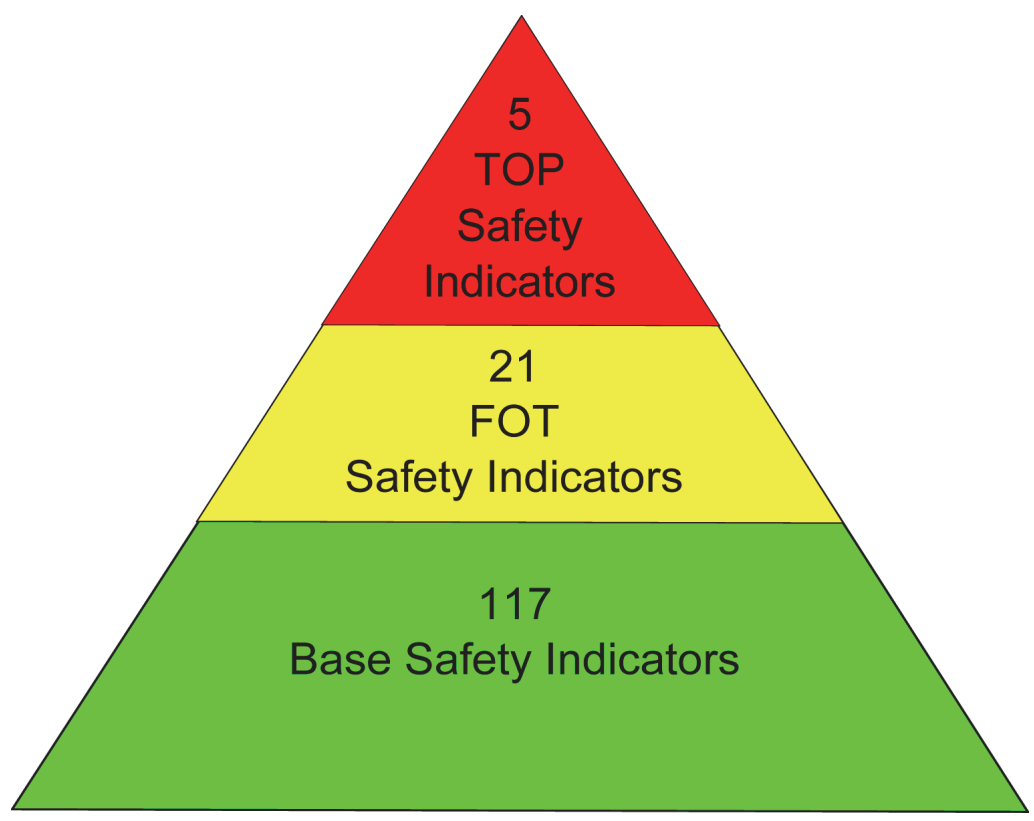

Figure 1: System of safety indicators.

purpose a system of safety indicators to classify incidents in public transport has been developed [4]. The system consists of three levels of aggregation as depicted in figure 1.

The full set of 117 base safety indicators is used to perform a classification at a very detailed level. The set of 21 FOT safety indicators at the second level comprises the 117 indicators, represents the first abstraction level and is covering more than $90 \%$ of the incident's risk. The highest level of aggregation, the TOP safety indicators can be seen as a "management summary" and are used for internal communication purposes of the Swiss department of transport. The main design goal of this system of indicators is the supervision of the safety performance with the possibility of identification of causes and responsible transport companies.

In this paper the 21 FOT safety indicators of level 2 are used to define and evaluate safety targets for Switzerland and for Swiss public transport companies.

The new proposed methodology provides a transparent safety monitoring system that can be used by the FOT to measure the effectiveness of safety measures and to provide starting points for company safety audits.

An incident database, described in the next section, provides the necessary input to perform the definition of safety targets and the evaluation of the safety performance on country and company level, both described in the methodology section. A summary of the paper can be found in the result section at the end of this paper, some considerations about things to do are discussed in the final outlook section. 


\section{Incident database analysis}

The incident database of the FOT was started in the year 2000 and records incidents of all modes of public transport (rail, tram, bus, ship, cableways). From the more than 14000 incidents most records are from the railway domain. The procedure of recording in that domain is well established and therefore approx. 8000 incidents were recorded from 2000 to 2009. These incidents are used as an input for the following statistical analyses.

\subsection{Statistical analysis}

Consistency checks were performed to evaluate the usability of the incidents stored in the database. Figure 2 shows that expected patterns in the dataset could be

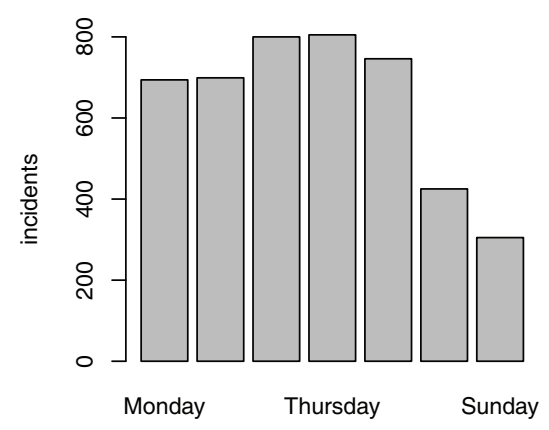

a) weekday

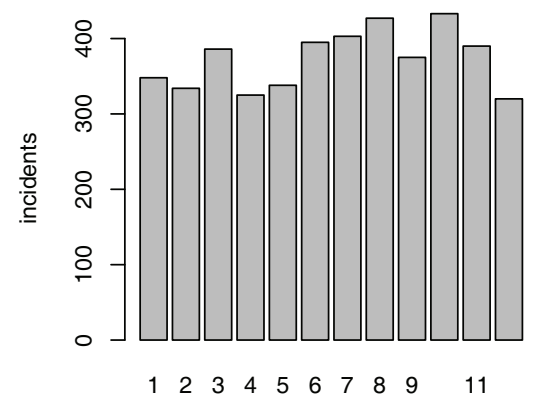

c) month

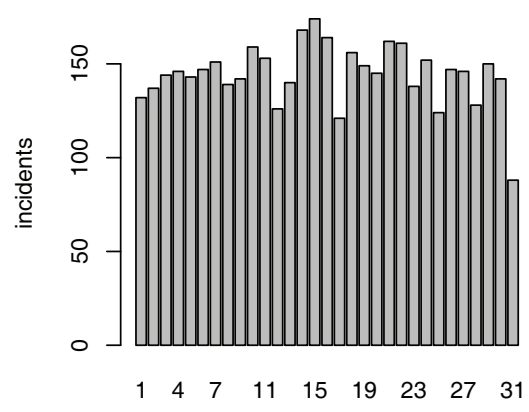

b) day of month

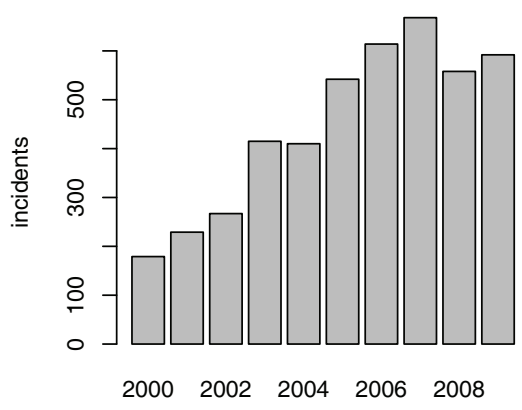

d) year

Figure 2: Statistical analyses of incidents. 
is less frequent on these days (a). Incidents are evenly distributed on days per month with fewer incidents on the 31st (b). Equally, incidents per month can be seen in (c). The only deviation of expectation is found in (d). The impression that the number of incidents increased over time needs an explanation. Two reasons could be identified. First the system of recording the incidents was modified in 2005 which lead to an increase of (recorded) incidents. The most significant increase is observed in incidents without personal injuries and incidents with light injuries. Secondly the system of recording the incidents needed some time to be established with the railway companies; therefore the data of the early two to three years is somewhat incomplete.

In order to eliminate the influence of the increase of number of incidents during the time period a number of rules for definition of relevant incident have been developed.

The numbers of incidents which caused a FWI for selected indicators are depicted in figure 3. It can be seen that indicators which involve collisions are well maintained since the beginning of data recording (EA11 and EB11).
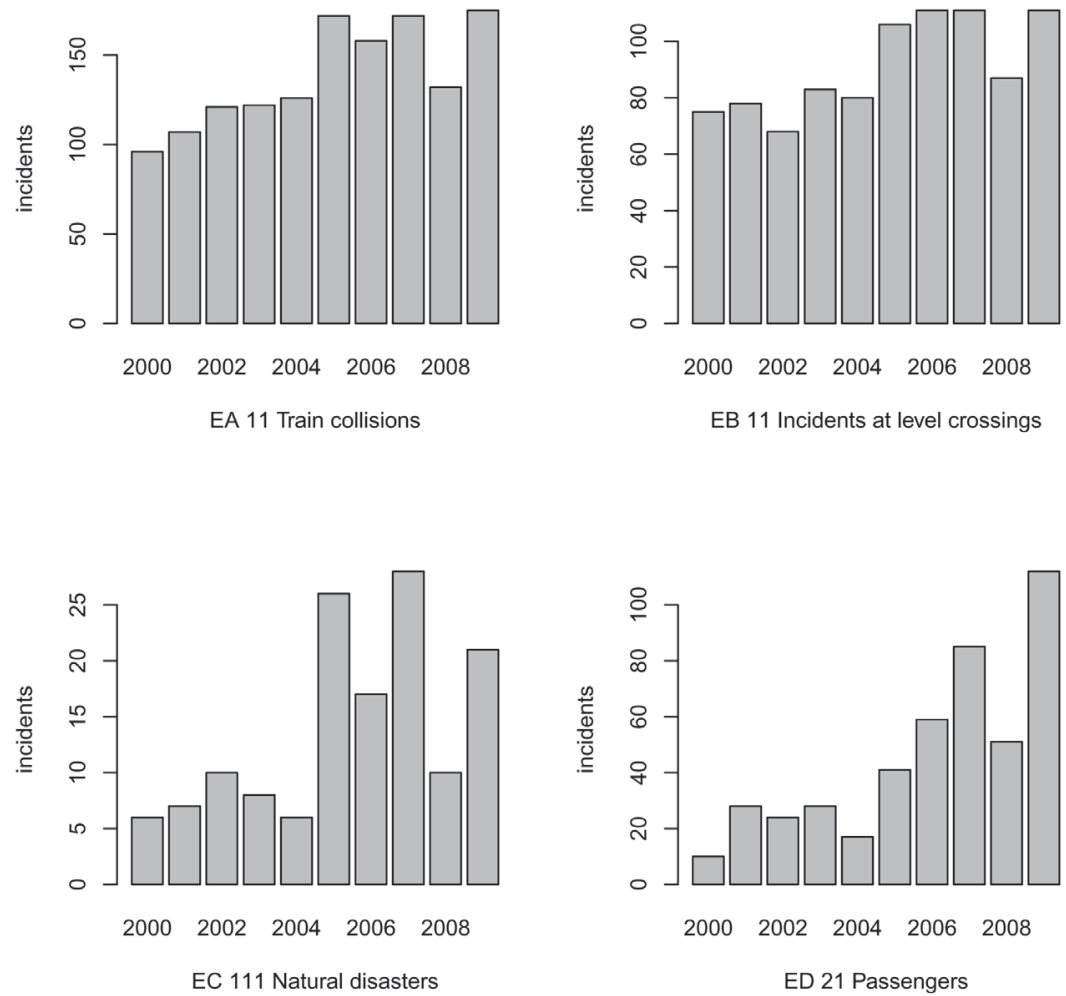

Figure 3: Numbers of (FWI)-incidents of selected indicators. 
Natural disasters are of a very random nature (EC 111). While the indicator for passengers (ED21) suggests, that the risk increased, the "growing" numbers were caused by changes in the data collection process. From 2005 it is mandatory to record incidents with light injuries, additionally railway companies are educated to improve their recording procedures.

\subsection{Distribution identification}

Each incident was assigned up to four of the 21 FOT safety indicators (table 1 and table 2), explaining what happened (EA indicators), where did it happen (EB indicator), why did the incident happen (EC indicators) and who was affected/harmed (ED indicators). For each of the 21 BAV safety indicators the mean time between failure rates (MTBF) were calculated and the distribution of the events identified (Figure 4). Furthermore a distinction was made between the overall number of incidents and the corresponding number of fatalities and weighted injuries (FWI) whereby

$$
F W I=\text { fatalities }+0.1 \cdot \text { serious injuries }+0.01 \cdot \text { light injuries }
$$

Table 1: Safety Targets: Number of incidents per million train kilometres.

\begin{tabular}{lrrr}
\hline Safety indicator & MIN & AVG & MAX \\
\hline EA 11 Train collisions & 0.289 & 0.312 & 0.336 \\
EA 12 Shunting collisions & 0.199 & 0.218 & 0.238 \\
EA 21 Train derailments & 0.111 & 0.125 & 0.141 \\
EA 22 Shunting derailments & 0.548 & 0.580 & 0.612 \\
EA 31 Train at danger & 0.305 & 0.329 & 0.353 \\
EA 411 Accident with human being & 0.196 & 0.215 & 0.234 \\
EA 421 Accident at work & 0.043 & 0.052 & 0.062 \\
EA 512 Vehicle fire & 0.045 & 0.055 & 0.065 \\
EA 52 Disturbances & 0.045 & 0.055 & 0.065 \\
EB 11 Incidents at level crossings & 0.444 & 0.473 & 0.502 \\
EC 111 Natural disasters & 0.067 & 0.078 & 0.090 \\
EC 21 Technical defect vehicle & 0.149 & 0.166 & 0.183 \\
EC 22 Technical defect infrastructure & 0.085 & 0.098 & 0.111 \\
EC 311 Signal passed at danger & 0.235 & 0.255 & 0.277 \\
EC 313 Spurious action shunting & 0.213 & 0.232 & 0.253 \\
EC 316 Spurious action work on track & 0.297 & 0.320 & 0.344 \\
EC 331 Spurious action presence in structure gauge & 0.077 & 0.089 & 0.101 \\
EC 342 Sabotage / Vandalism & 0.036 & 0.044 & 0.053 \\
\hline
\end{tabular}


Table 2: Safety Targets: Incident consequence (FWI) per million train kilometres.

\begin{tabular}{llll}
\hline Safety indicator & MIN & AVG & MAX \\
\hline EA 11 Train collisions & 0.086 & 0.096 & 0.11 \\
EA 12 Shunting collisions & 0.0066 & 0.0079 & 0.0094 \\
EA 21 Train derailments & 0.0008 & 0.0019 & 0.0032 \\
EA 22 Shunting derailments & 0.00069 & 0.0011 & 0.0016 \\
EA 31 Train at danger & 0.00053 & 0.0011 & 0.0017 \\
EA 411 Accident with human being & 0.040 & 0.044 & 0.048 \\
EA 421 Accident at work & 0.012 & 0.015 & 0.018 \\
EA 512 Vehicle fire & 0.00005 & 0.00010 & 0.00015 \\
EA 52 Disturbances & 0.00067 & 0.0011 & 0.0016 \\
EB 11 Incidents at level crossings & 0.053 & 0.059 & 0.066 \\
EC 111 Natural disasters & 0.00003 & 0.00010 & 0.00020 \\
EC 21 Technical defect vehicle & 0.0003 & 0.0004 & 0.0005 \\
EC 22 Technical defect infrastructure & 0.00005 & 0.00018 & 0.00037 \\
EC 311 Signal passed at danger & 0.0020 & 0.0033 & 0.0049 \\
EC 313 Spurious action shunting & 0.0034 & 0.0048 & 0.0064 \\
EC 316 Spurious action work on track & 0.0075 & 0.0091 & 0.0109 \\
EC 331 Spurious action presence in structure gauge & 0.039 & 0.045 & 0.052 \\
EC 342 Sabotage / Vandalism & 0.00018 & 0.00034 & 0.00055 \\
ED 21 Passengers (all) & 0.040 & 0.043 & 0.047 \\
ED 21a Passengers (without personal fault) & 0.009 & 0.011 & 0.014 \\
ED 22 Staff & 0.023 & 0.026 & 0.030 \\
ED 25 Third persons (all) & 0.14 & 0.15 & 0.16 \\
ED 25a Third persons (without personal fault) & 0.0017 & 0.0023 & 0.0031 \\
\hline & & &
\end{tabular}

The years 2000 and 2001 were not taken into account for this calculation, as missing incidents would suggest a smaller risk of an incident to happen. To make these MTBF rates more comparable they were put in to relation to train kilometres. The details of the methodology are described in the next section.

\section{Methodology}

\subsection{Safety targets and statistical significance}

About 4600 relevant incidents from the years 2002 to 2009 could be used for the calculations of Swiss safety targets. Despite of a relatively high number of incidents some of the safety indicators only show a very low count of 
MTBF FWI

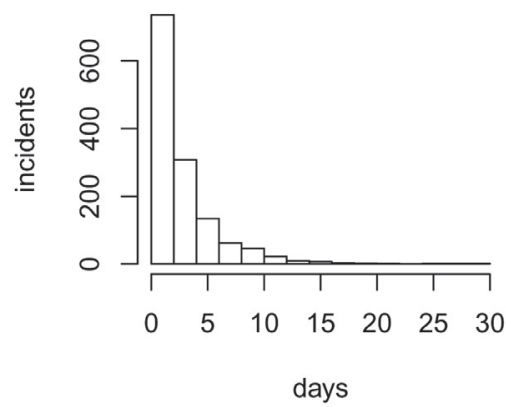

QQ plot with outliers, Method II exponential distribution, $\mathbf{R} 2 \mathbf{=} \mathbf{0 . 9 8 9 8}$

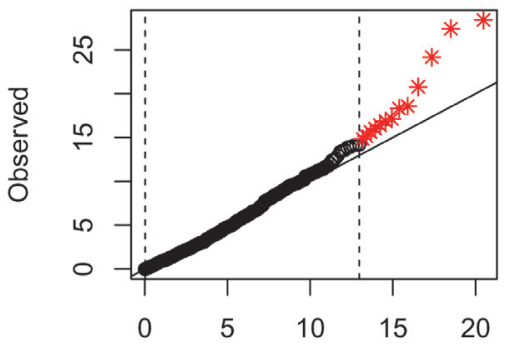

Predicted

Figure 4: MTBF rates of incidents with FWI and test for exponential distribution.

incidents (e.g. EC111 natural disasters). If data is treated on a company level this problem is even more present. To overcome the difficulties of small numbers, significance levels were calculated for every safety indicator according to its (negative exponential) distribution and its MTBF, thus resulting not in a single value for a safety indicator, but in a from-to range (equation 2) [5]. With these ranges the safety targets for all 21 safety indicators for Switzerland were calculated from the incidents of 2002 to 2009.

For each indicator annual frequencies (number of incidents/year) and consequences (number of FWI/year) as well as their scaled values by millions of train kilometres are computed (see example of incidents/mio. train kilometres in table 1 and FWI/mio. train kilometres in table 2). The methodology differentiates in case of passengers (ED21) and third persons (ED25) the consequences with and without personal fault. These safety targets are taken as a reference for assessment on country and company level described in the next section.

$$
\frac{2 n \bar{x}}{\chi_{2 n, 1-\alpha}^{2}} \leq \frac{1}{\lambda} \leq \frac{2 n \bar{x}}{\chi_{2 n, \alpha}^{2}}
$$

$\frac{1}{\lambda}: \quad$ Mean Time Between Failures (MTBF)

$\alpha$ : Level of confidence (here 0,05 )

$n$ : Number of measurements i.e. degrees of freedom of $\chi^{2}$ distribution

$\chi^{2}: \quad$ Value of the $\chi^{2}$ distribution with $\mathrm{n}$ degrees of freedom

$\bar{x}$ : Estimated mean value 


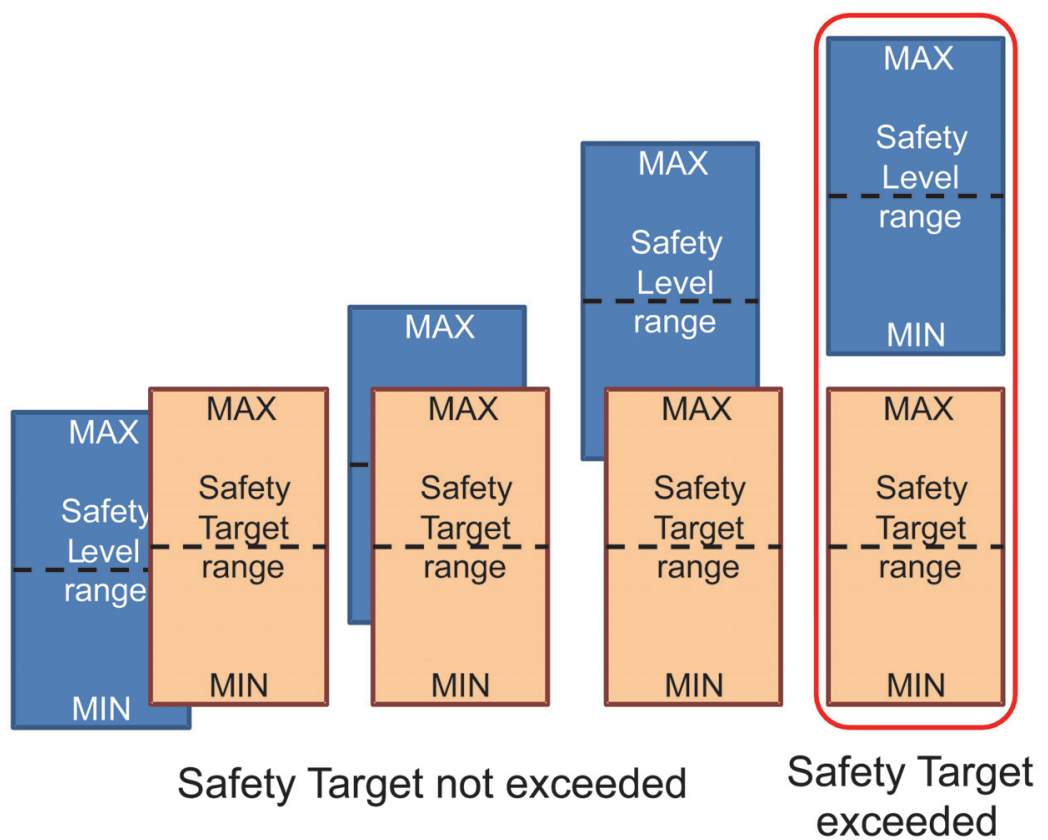

Figure 5: Comparison of safety targets.

\subsection{Safety level of the country}

Evaluation of the safety performance on the country level is carried out by comparison of the safety targets with the indicator value corresponding to a particular year. A deterioration of the safety performance will be identified in the case when the low limit of the indicator's safety range is higher than the upper limit of the target's safety range. An example of the evaluation is shown on figure 5.

Evaluating the incident data from the year 2010 only three indicators refer to a deterioration of the safety performance (EA 411, EB 11, EC 311). In all these cases the exceeding of the target's safety ranges concerns the frequency but not consequences. This is an indication, that here the most probable reason for the deterioration is the improvement of incident reporting's discipline.

\subsection{Safety level of railway companies}

Each incident of the dataset is tagged with a "responsible" company; therefore it is possible to divide the whole dataset in company based datasets (currently 48). For each of the 48 companies train kilometre data (accumulative train trip length) for the years 2006 to 2009 was available for standardisation. To get a suitable number of incidents per company all incidents from the four years were added up. The same procedure of calculating ranges of significance was applied (see 3.2). 
Due to the small number of incidents per company the above mentioned ranges are bigger than on a country level. With the ranges on the Swiss country level and the ranges for each company a scale was designed and applied, which is described in the next section.

\subsection{Ranking of railway companies}

The ranges for each of the 21 safety indicators for the country level calculated from the years 2002 to 2009 were taken as a reference (see 3.2). The ranges of the 21 safety indicators for each of the 48 companies calculated from 2006 to 2009 were compared against the country reference. For each comparison a value from 1 (safety level is within range) to $\mathrm{X}$ (safety level lies $\mathrm{X}$ times higher than allowed) was calculated (figure 5), for the absolute number of accidents, as well as for the FWIs. The values are added up and can be used to compare the safety levels of companies (see ranking in figure 6).

\section{Results}

With the proposed methodology it is possible to generate safety targets on a country level that still offer a detailed insight into the causes of the incidents. As the same calculations are applied to company data it is easy to rate the companies safety performance and to compare companies to each other. The methodology will be used by the FOT and will be the base for a tool to automate the calculation processes.

The first results show, that the evaluation method can be used for transport companies with annual performance higher than 2.5 million train kilometres (about $1 \%$ of Swiss railway transport volume). This concerns 12 transport companies. Other 16 companies can be evaluated only partially and the remaining companies (20) cannot be evaluated at all (up to rank 29, see figure 6) due to statistically insignificant incident data. In these companies the audits and inspections will be the main reference in the supervision of the safety performance.

\section{Outlook}

The method is currently applied to transportation companies offering public transport services and goods transportation companies. Infrastructure providers do not generate train kilometres as a statistic and could not yet be integrated into the comparison. In a next step an appropriate standardisation will be applied to incorporate all types of transport companies. The evaluation method of comparing safety targets will be improved by a more sophisticated procedure and therefore the presented numbers should be seen as preliminary results. 


\begin{tabular}{|c|c|c|c|c|c|}
\hline Ranking & \begin{tabular}{|l} 
Railway \\
Company
\end{tabular} & Risk Number & $\begin{array}{l}\text { Nr.of eval. } \\
\text { Indicators }\end{array}$ & $\begin{array}{l}\text { Nr. of eval. } \\
\text { Indicators }>1\end{array}$ & Tendency \\
\hline 1 & $\overline{R C 1}$ & 5 & 8 & 8 & $-0,971$ \\
\hline 2 & RC2 & 2 & 2 & 1 & 2 \\
\hline 3 & RC3 & 2 & 8 & 3 & $-0,6$ \\
\hline 4 & RC4 & 1,952 & 21 & 10 & $-0,333$ \\
\hline 5 & RC5 & 1,5 & 12 & 5 & 0,244 \\
\hline 6 & RC6 & 1,4 & 5 & 1 & -1 \\
\hline 7 & RC7 & 1,333 & 9 & 3 & $-0,6$ \\
\hline 8 & RC8 & 1,25 & 20 & 4 & 0,055 \\
\hline 9 & RC9 & 1,222 & 9 & 2 & 0,4 \\
\hline 10 & RC10 & 1,167 & 6 & 1 & $-0,667$ \\
\hline 11 & RC11 & 1,167 & 18 & 3 & $-0,055$ \\
\hline 12 & RC12 & 1,083 & 12 & 1 & 0 \\
\hline 13 & RC13 & 1,048 & 21 & 1 & 0,048 \\
\hline 14 & RC14 & 1 & 1 & 0 & 0 \\
\hline 15 & RC15 & 1 & 1 & 0 & 0 \\
\hline 16 & RC16 & 1 & 1 & 0 & 0 \\
\hline 17 & RC17 & 1 & 2 & 0 & 0 \\
\hline 18 & RC18 & 1 & 2 & 0 & 0 \\
\hline 19 & RC19 & 1 & 5 & 0 & 0 \\
\hline 20 & RC20 & 1 & 6 & 0 & 0 \\
\hline 21 & RC21 & 1 & 7 & 0 & 0 \\
\hline 22 & $\mathrm{RC} 22$ & 1 & 9 & 0 & 0 \\
\hline 23 & RC23 & 1 & 12 & 0 & 0 \\
\hline 24 & RC24 & 1 & 13 & 0 & 0 \\
\hline 25 & RC25 & 1 & 14 & 0 & 0 \\
\hline 26 & RC26 & 1 & 15 & 0 & 0 \\
\hline 27 & RC27 & 1 & 20 & 0 & 0 \\
\hline 28 & $\mathrm{RC} 28$ & 1 & 20 & 0 & 0 \\
\hline 29 & RC29 & 0 & 0 & 0 & 0 \\
\hline 30 & RC30 & 0 & 0 & 0 & 0 \\
\hline 31 & RC31 & 0 & 0 & 0 & 0 \\
\hline 32 & RC32 & 0 & 0 & 0 & 0 \\
\hline 33 & RC33 & 0 & 0 & 0 & 0 \\
\hline 34 & RC34 & 0 & 0 & 0 & 0 \\
\hline 35 & RC35 & 0 & 0 & 0 & 0 \\
\hline 36 & RC36 & 0 & 0 & 0 & 0 \\
\hline 37 & RC37 & 0 & 0 & 0 & 0 \\
\hline 38 & RC38 & 0 & 0 & 0 & 0 \\
\hline 39 & RC39 & 0 & 0 & 0 & 0 \\
\hline 40 & RC40 & 0 & 0 & 0 & 0 \\
\hline 41 & RC41 & 0 & 0 & 0 & 0 \\
\hline 42 & RC42 & 0 & 0 & 0 & 0 \\
\hline 43 & RC43 & 0 & 0 & 0 & 0 \\
\hline 44 & RC44 & 0 & 0 & 0 & 0 \\
\hline 45 & RC45 & 0 & 0 & 0 & 0 \\
\hline 46 & RC46 & 0 & 0 & 0 & 0 \\
\hline 47 & RC47 & 0 & 0 & 0 & 0 \\
\hline 48 & RC48 & 0 & 0 & 0 & 0 \\
\hline
\end{tabular}

Figure 6: Company comparison. 


\section{References}

[1] Evans, A.W., Fatal train accidents on Europe's railways: 1980-2009. Accident Analysis and Prevention, 43 (5), 2012.

[2] Evans, A.W., Fatal train accidents on britain's main line railways: End of 2011 analysis. Working Paper, Centre of Transport Studies, Imperial College London, 2012.

[3] Federal Office of Transport, FOT Safety Concept. http://www.bav . admin.ch/themen/verkehrspolitik/00501/01579/,2009

[4] Federal Office of Transport, Weiterentwicklung Sicherheitskonzept BAV: Konkretisierung der Sicherheitsziele, 1. Schritt: Sicherheitsindikatoren BAV. FOT Internal Report, 2011.

[5] Schnieder, E., Maße, Modelle und Methoden (VDI-Buch). Springer: Berlin, Heidelberg, 2012. 